\title{
Tracheostomy Practice in Mechanically Ventilated Patients With SARS- CoV-2 Induced Acute Respiratory Distress Syndrome: a Single-center Retrospective Study With Focus on Tracheomalacia
}

\author{
Marcello Guarnieri \\ University of Milano-Bicocca: Universita degli Studi di Milano-Bicocca \\ Patrizia Andreoni \\ Niguarda Ca Granda Hospital: Azienda Socio Sanitaria Territoriale Grande Ospedale Metropolitano Niguarda \\ Hedwige Gay \\ University of Milano-Bicocca: Universita degli Studi di Milano-Bicocca \\ Riccardo Giudici \\ Niguarda Ca Granda Hospital: Azienda Socio Sanitaria Territoriale Grande Ospedale Metropolitano Niguarda \\ Maurizio Bottiroli \\ Niguarda Ca Granda Hospital: Azienda Socio Sanitaria Territoriale Grande Ospedale Metropolitano Niguarda \\ Michele Mondino \\ Niguarda Ca Granda Hospital: Azienda Socio Sanitaria Territoriale Grande Ospedale Metropolitano Niguarda \\ Gianpaolo Casella \\ Niguarda Ca Granda Hospital: Azienda Socio Sanitaria Territoriale Grande Ospedale Metropolitano Niguarda \\ Osvaldo Chiara \\ Niguarda Ca Granda Hospital: Azienda Socio Sanitaria Territoriale Grande Ospedale Metropolitano Niguarda \\ Oscar Morelli \\ Niguarda Ca Granda Hospital: Azienda Socio Sanitaria Territoriale Grande Ospedale Metropolitano Niguarda \\ Serena Conforti \\ Niguarda Ca Granda Hospital: Azienda Socio Sanitaria Territoriale Grande Ospedale Metropolitano Niguarda \\ Thomas Langer ( $\square$ thomas.Langer@unimib.it ) \\ University of Milano-Bicocca https://orcid.org/0000-0002-9725-8520 \\ Roberto Fumagalli \\ University of Milano-Bicocca: Universita degli Studi di Milano-Bicocca
}

\section{Research}

Keywords: Severe Acute Respiratory Syndrome Coronavirus 2, Mechanical Ventilation, Airway Management, Tracheostomy, Tracheomalacia

Posted Date: January 21st, 2021

DOI: https://doi.org/10.21203/rs.3.rs-150959/v1

License: (c) (i) This work is licensed under a Creative Commons Attribution 4.0 International License. Read Full License 


\section{Abstract}

Background: The SARS-CoV-2 pandemic increased the number of patients needing invasive mechanical ventilation, either through an endotracheal tube or through a tracheostomy. Tracheomalacia is a rare, but potentially severe complication of mechanical ventilation, which can significantly complicate the weaning process. Aim of this study was to describe the strategies of airway management in mechanically ventilated patients with respiratory failure due to SARS-CoV-2, the incidence of severe tracheomalacia, and investigate the factors associated with its occurrence.

Methods. Retrospective, single-center study performed in an Italian teaching hospital. All adult patients admitted to the Intensive Care Unit (ICU) between February 24 and June 30, 2020, treated with invasive mechanical ventilation for respiratory failure caused by SARS-CoV-2 were included. Clinical data were collected on the day of ICU admission, while information regarding airway management was collected daily.

Results. A total of 151 patients were included in the study. On admission, ARDS severity was mild in $21 \%$, moderate in $62 \%$, and severe in $17 \%$ of the cases, with an overall mortality of $39.7 \%$. A tracheostomy was performed in 73 (48.3\%) patients: open surgical technique in 54 patients (74\%) and percutaneous Ciaglia technique in 19 patients (26\%). Patients in whom a tracheostomy was performed had, compared to the other patients, a longer duration of mechanical ventilation and longer ICU and hospital length of stay. Tracheomalacia was diagnosed in 8 (5\%) patients. The factors associated with tracheomalacia were female sex, obesity, and tracheostomy.

Conclusions. In our population, approximately $50 \%$ of patients with ARDS due to SARS-CoV-2 were tracheostomized. Tracheostomized patients had a longer ICU and hospital length of stay. Five percent of our population was diagnosed with tracheomalacia. This percentage is 10 times higher than what is reported in available literature and the underlying mechanisms are not fully understood.

\section{Background}

Italy was hit by the first pandemic wave of a new coronavirus [1] subsequently named Severe Acute Respiratory Syndrome Coronavirus 2 (SARSCoV-2) at the end of February 2020. The novel virus causes a disease named Coronavirus Disease 2019 (COVID-19), which has a wide variety of clinical presentations, ranging from asymptomatic carriers to severe cases of acute respiratory distress syndrome (ARDS). Intensive care unit (ICU) admission, endotracheal intubation, and mechanical ventilation are frequently required in patients with severe COVID-19 [2-6].

Tracheostomy is a common procedure in the ICU, in particular in difficult-to-wean patients [7]. Tracheostomy can be performed either percutaneously or surgically [8]. The first is associated with fewer infections and bleeding, while the latter guarantees less risk of posterior wall injury and accidental decannulation [8]. Acquired tracheomalacia is a rare, but potentially life-threatening complication of intubation and mechanical ventilation [9]. The incidence of and risk factors associated with tracheomalacia in critically ill patients with COVID-19 are currently unknown.

The aims of the present study are, therefore: (i) to describe the strategies of airway management in critically ill patients with COVID-19; (ii) to describe the incidence of tracheomalacia; and (iii) to investigate possible factors associated with the development of tracheomalacia.

\section{Methods}

This single-center observational retrospective study was approved by the Local Ethical Committee (approval number: 593-06102020). The need for informed consent from individual patients was waived owing to the retrospective nature of the study. This study followed the Strengthening the Reporting of Observational Studies in Epidemiology (STROBE) statement guidelines for observational studies.

All patients admitted between February 22, 2020, and June 30, 2020, inclusive for those days, to the 5 COVID-19 ICUs of the Grande Ospedale Metropolitano Niguarda were screened for eligibility. Laboratory-confirmed SARS-CoV-2 infection, (i.e. positive result of real-time reverse transcriptase-polymerase chain reaction assay of nasal or pharyngeal swabs) and ICU admission for acute respiratory failure constituted the inclusion criteria. Exclusion criteria were age < 18 years, admission for causes other than respiratory failure, and patients admitted for respiratory failure, but treated exclusively with non-invasive respiratory support.

The clinical management followed local protocols and suggestions from scientific societies [10]. The decision to perform a tracheostomy was at the discretion of the attending physicians. Tracheostomy was considered in case of predicted prolonged weaning from mechanical ventilation and was performed either by two surgeons, with the assistance of an anesthesiologist (surgical technique), or by two anesthesiologists (percutaneous technique).

Patients included in the analysis were divided into 2 groups according to their airway management: (i) patients treated with endotracheal tube only, (ii) patients in whom a tracheostomy was performed in the ICU. 
A subgroup of patients in whom tracheomalacia was first suspected clinically, and then confirmed through an endoscopic evaluation (performed by an experienced thoracic surgeon, SC) was identified. Tracheomalacia was defined, according to the available literature, as a weakness of the trachea, likely due to a reduction and/or atrophy of the elastic fibers, determining a tendency to tracheal collapse [9].

\section{Data collection}

Clinical data were extracted from the patient data management system and a unique database was created using the web-based software RedCap (RedCap electronic data capture tools). For every included patient we recorded demographic and anthropometric data, comorbidities, and medical history. Clinical data, including but not limited to, severity scores, vital signs, respiratory mechanics, and gas exchange were collected on the day of admission to the ICU. Information regarding airway management, i.e. performance of a tracheostomy, extubation, or decannulation was collected daily until ICU discharge or patient's death. The final date of follow-up for patient outcomes was July 31,2020 , and the following patient outcomes were recorded: ICU and hospital survival, ICU and hospital length of stay (LOS), duration of invasive mechanical ventilation, incidence of tracheostomy, and incidence of tracheomalacia.

\section{Statistical Analysis}

All data were tested for homogeneity of variance and normality of distribution using the Shapiro-Wilk test. Normally distributed data were expressed as mean \pm standard deviation, while non-normally distributed data were reported as median and interquartile range. Binary data were summarized as percentages frequency of occurrence. To compare study groups (tracheostomy vs. non-tracheostomy and tracheomalacia vs. non-tracheomalacia), Mann-Whitney rank-sum test, and $\chi 2$ or Fisher exact test were used for nonparametric continuous variables and categorical variables, respectively. All statistical tests were 2-tailed, and statistical significance was defined as a P-value below 0.05 . The analyses were performed using Sigmaplot v. 12.0 (Systat Software Inc., USA).

\section{Results}

A total of 177 patients were admitted to the ICU with laboratory-confirmed SARS-CoV-2 infection during the study period. Twenty-six patients were excluded (in 21 patients the admission was not primarily for respiratory failure and 5 patients received non-invasive ventilation exclusively), leaving 151 patients for analysis (Fig. 1).

Table 1 summarizes baseline characteristics of the study population at ICU admission and their clinical outcomes. One hundred sixteen (77\%) patients were male and 50 (33\%) were obese (Body mass index $>30 \mathrm{~kg} / \mathrm{m}^{2}$ ). The most common comorbidities were hypertension (48\%), diabetes mellitus (15\%), and chronic obstructive pulmonary disease (12\%). At ICU admission, median APACHE and SOFA scores were 23 [21-27] and 5 [3-7], respectively. 
Table 1

Patients' characteristics at admission in ICU and outcome. Comparison between tracheostomized patients and patients treated with endotracheal tube exclusively.

\begin{tabular}{|c|c|c|c|c|}
\hline Variables & $\begin{array}{l}\text { Overall population } \\
(n=151)\end{array}$ & $\begin{array}{l}\text { Endotracheal Intubation only } \\
(n=78)\end{array}$ & $\begin{array}{l}\text { Tracheostomy } \\
(n=73)\end{array}$ & P-value \\
\hline Males, n (\%) & $116(76.8)$ & 66 (84.6) & $50(68.5)$ & 0.031 \\
\hline Age, years & $59 \pm 11$ & $59 \pm 12$ & $59 \pm 10$ & 0.814 \\
\hline $\mathrm{BMI}, \mathrm{kg} / \mathrm{m}^{2}$ & $28[25-31]$ & $27[26-31]$ & 28 [25-32] & 0.923 \\
\hline Obesity (BMI > 30), n (\%) & $50(33.1)$ & $25(32.1)$ & $25(34.2)$ & 0.910 \\
\hline Chronic Ischemic Cardiovascular disease, n (\%) & $8(5.3)$ & $7(9.0)$ & $1(1.4)$ & 0.085 \\
\hline Hypertension, n (\%) & $72(47.7)$ & $38(48.7)$ & $34(46.6)$ & 0.920 \\
\hline Diabetes, n (\%) & $23(15.2)$ & $13(16.7)$ & $10(13.7)$ & 0.779 \\
\hline Chronic Kidney Failure, n (\%) & $2(1.3)$ & $1(1.3)$ & $1(1.4)$ & 0.506 \\
\hline Neoplasia, n (\%) & $6(4.0)$ & $4(5.1)$ & $2(2.7)$ & 0.738 \\
\hline Hepatic disease, n (\%) & $5(3.3)$ & $2(2.6)$ & $3(4.1)$ & 0.940 \\
\hline Chronic Obstructive Pulmonary disease, $n$ (\%) & $18(11.9)$ & $10(12.8)$ & $8(11.0)$ & 0.919 \\
\hline Immunosuppression, n (\%) & $4(2.6)$ & $4(5.1)$ & $0(0.0)$ & 0.146 \\
\hline Patients with no comorbidities, n (\%) & $35(23.2)$ & $16(20.5)$ & $19(26.0)$ & 0.542 \\
\hline APACHE score & 23 [21-27] & 23 [21-27] & 24 [22-27] & 0.784 \\
\hline SOFA score & $5[3-7]$ & $5[3-7]$ & $4[4-6]$ & 0.596 \\
\hline $\mathrm{PaO}_{2} / \mathrm{FiO}_{2}$ ratio & 153 [113-195] & $152[108-201]$ & $153[117-190]$ & 0.960 \\
\hline ICU length of stay, days & $14[9-27]$ & $9[5-14]$ & 27 [17-39] & $<0.001$ \\
\hline ICU mortality, n (\%) & $60(39.7)$ & $35(44.9)$ & $25(34.2)$ & 0.243 \\
\hline Hospital length of stay, days & $26[14-46]$ & $17[9-26]$ & $45[27-58]$ & $<0.001$ \\
\hline Hospital mortality, $n(\%)$ & $64(42.4)$ & $36(46.2)$ & $28(38.4)$ & 0.421 \\
\hline \multicolumn{5}{|c|}{$\begin{array}{l}\text { Data are expressed as } n(\%) \text {, mean } \pm \text { standard deviation, or median [interquartile range] as appropriate. SOFA score, APACHE score, and } \\
\mathrm{PaO}_{2} / \mathrm{FiO}_{2} \text { ratio refer to data at ICU admission. }\end{array}$} \\
\hline
\end{tabular}

At admission, ARDS severity was mild in $21 \%$, moderate in $62 \%$, and severe in $17 \%$ of the cases. One or more infective complications (microbiologically-confirmed) were reported in 81 patients (54\%) during the ICU stay. Fifty-six (37\%) patients developed sepsis and in 32 cases $(21 \%)$ it worsened into septic shock. The median duration of antibiotic therapy was 6 [2-15] days. Overall, median ICU and hospital length of stay were 14 [9-27] days and 26 [14-46] days, respectively. Sixty patients (40\%) died in the ICU, mortality increased according to disease severity at admission $(25 \%, 40 \%$, and $58 \%, p=0.041$, for mild, moderate, and severe ARDS, respectively).

A tracheostomy was performed in $73(48 \%)$ of patients. There was no significant difference in the performance of tracheostomy according to ARDS severity at admission $(41 \%, 51 \%$, and $50 \%, p=0.62$ for mild, moderate, and severe ARDS, respectively). The approach was surgical in 54 $(74 \%)$ cases and percutaneous, using a single dilator Ciaglia technique in the remaining $19(26 \%)$ cases. The median time of tracheostomy performance was 11 days after tracheal intubation, with an interquartile range of 8 to 15 days. Differences between the subgroup treated exclusively with endotracheal intubation and the subgroup undergoing a tracheostomy are reported in Table 1.

Mortality in the ICU did not differ between tracheostomized patients and patients treated exclusively with endotracheal intubation (34\% vs. $45 \%$, $p=0.243)$. Patients in whom a tracheostomy was performed had a significantly longer duration of mechanical ventilation (25 [15-36] vs. 8 [512] days, $p<0.001)$ and both ICU (27 [17-39] vs. 9 [5-14] days, $p<0.001)$ and hospital (45 [27-58] vs. 17 [9-26] days, $p<0.001)$ length of stay. 
Eight two \% of tracheostomized patients developed at least one infective complication, as compared to $27 \%$ in patients treated with endotracheal tube exclusively $(\mathrm{p}<0.001)$. Moreover, sepsis and septic shock during the ICU stay occurred more often in tracheostomized patients $(60 \%$ vs. $15 \%$, $p<0.001$ and $32 \%$ vs $12 \%, p=0.005$, respectively). Bacterial pneumonia was the most common infection ( $62 \%$ vs. $23 \%, p<0.001)$, followed by bloodstream infections ( $64 \%$ vs. $22 \%, p<0.001)$. The median duration of antibiotic therapy was longer in tracheostomized patients $(15$ [ $6-21$ vs. 3 [0-6] days, $p<0.001)$.

Tracheomalacia was diagnosed in 8 (5\%) of studied patients. The diagnosis was performed 27 [21-32] days after endotracheal intubation. Compared to the remaining population (Table 2), more patients in whom tracheomalacia was diagnosed were female $(75 \%$ vs. $20 \%, p=0.002$; Odds Ratio 11.8, Confidence Interval [2.3-61.5]) and obese (88\% vs. 30\%, p = 0.003; OR 16.3, $\mathrm{Cl}$ [1.9-136.4]). All patients diagnosed with tracheomalacia were treated with a tracheostomy for airway management ( $100 \%$ vs. $45 \%, p=0.008)$. No difference was found regarding the use of the surgical approach ( $87.5 \%$ vs. $72.3 \% p=0.671$ with surgical approach), the timing of tracheostomy (11 [7-14] days vs. 11 [8-17] days, $p=$ 0.371 ), and decannulation (35 [23-56] days vs. 19 [14-33] $p=0.108$ ) comparing patients that developed tracheomalacia with the remaining population. Conversely, the duration of mechanical ventilation $(29$ [22-34] vs. 13 [8-24] days, $p=0.007)$ was significantly longer in patients diagnosed with tracheomalacia.

Table 2

Comparison between patients with and without a diagnosis of tracheomalacia.

\begin{tabular}{|c|c|c|c|}
\hline Variables & $\begin{array}{l}\text { Without Tracheomalacia } \\
n=143(95 \%)\end{array}$ & $\begin{array}{l}\text { With Tracheomalacia } \\
n=8(5 \%)\end{array}$ & P-value \\
\hline Males, n (\%) & $114(79.7)$ & $2(25.0)$ & 0.002 \\
\hline Age, years & $59 \pm 11$ & $55 \pm 14$ & 0.313 \\
\hline $\mathrm{BMI}, \mathrm{kg} / \mathrm{m}^{2}$ & $27[25-31]$ & $35[32-40]$ & 0.007 \\
\hline Obesity (BMI > 30), n (\%) & $43(30.1)$ & $7(87.5)$ & 0.003 \\
\hline Chronic Ischemic Cardiovascular disease n (\%) & $8(5.6)$ & $0(0.0)$ & 0.902 \\
\hline Hypertension, n (\%) & $67(46.9)$ & $5(62.5)$ & 0.618 \\
\hline Diabetes, n (\%) & $23(16.1)$ & $0(0.0)$ & 0.486 \\
\hline Chronic Kidney Failure, n (\%) & $2(1.4)$ & $0(0.0)$ & 0.210 \\
\hline Neoplasia, n (\%) & $5(3.5)$ & $1(12.5)$ & 0.735 \\
\hline Hepatic disease, n (\%) & $5(3.5)$ & $0(0.0)$ & 0.633 \\
\hline Chronic Obstructive Respiratory disease, n (\%) & $17(11.9)$ & $1(12.5)$ & 0.611 \\
\hline Immunosuppression, n (\%) & $4(2.8)$ & $0(0.0)$ & 0.515 \\
\hline Patients with no comorbidities, n (\%) & $33(23.1)$ & $2(25.0)$ & 0.760 \\
\hline APACHE score & $23[21-26]$ & $25[20-28]$ & 0.729 \\
\hline SOFA score & $5[3-7]$ & $4[3-6]$ & 0.632 \\
\hline $\mathrm{PaO}_{2} / \mathrm{FiO}_{2}$ ratio & $153[115-196]$ & $119[85-163]$ & 0.082 \\
\hline One or more Infections developed during ICU stay, n (\%) & $73(51.0)$ & $8(100.0)$ & 0.019 \\
\hline Tracheostomy, n (\%) & $65(45.5)$ & $8(100.0)$ & 0.008 \\
\hline Tracheostomy Technique, surgical, n (\%) & $47(72.3)$ & $7(87.5)$ & 0.671 \\
\hline ICU length of stay, days & $14[8-26]$ & $29[24-41]$ & 0.006 \\
\hline ICU mortality, n (\%) & $58(40.6)$ & $2(25.0)$ & 0.614 \\
\hline Hospital length of stay, days & $25[13-43]$ & $55[35-90]$ & 0.002 \\
\hline Hospital mortality, n (\%) & $61(42.7)$ & $3(37.5)$ & 0.936 \\
\hline \multicolumn{4}{|c|}{ Data are expressed as $n(\%)$, mean \pm standard deviation, or median [interquartile range] as appropriate. } \\
\hline
\end{tabular}


All patients with tracheomalacia developed one or more microbiologically-confirmed infections during ICU stay (100\% vs $51 \%$, $p=0.019)$. Sepsis was reported more frequently in patients with tracheomalacia $(75 \%$ vs $35 \%, p=0.057)$ and the median duration of antibiotic therapy was longer in patients who developed tracheomalacia (22 [5-28] vs. 6 [2-15] days, $p=0.018$ ). Similarly, ICU and hospital length of stay were significantly longer in patients diagnosed with tracheomalacia (29 [24-41] vs. 14 [8-26] days, $p=0.006$ and 55 [35-90] vs. 25 [13-43] days, $p=0.002$, respectively). Three cases of airway fistula were reported among patients with tracheomalacia (37\%). ICU and hospital mortality were not different between patients with tracheomalacia and the remaining patients $(25 \%$ vs. $41 \% p=0.614$ and $38 \%$ vs. $43 \%, p=0.936)$.

\section{Discussion}

In this single-center, retrospective observational study we analyzed the modalities of airway management in 151 critically ill, mechanically ventilated patients with COVID-19, admitted to the ICUs of one of the largest hospitals in Italy, during the first SARS-CoV-2 pandemic wave. In addition, we focused our attention on patients that were diagnosed with tracheomalacia during their ICU length of stay.

A major finding of our study is that a tracheostomy was performed in almost $50 \%$ of patients treated with invasive mechanical ventilation for COVID-19 related respiratory failure and that in our cohort of patients, the incidence of tracheostomy was not different according to ARDS severity. These findings differ markedly from what has been described in the "classic" ARDS population. Indeed, a recent worldwide observational study evaluating the incidence and characteristics of ARDS patients in the ICU, described that a tracheostomy was performed in $13 \%$ of the overall ARDS population [11], increasing from $9.6 \%$ in mild to $14.5 \%$ in severe ARDS patients [12]. On the contrary, recent literature regarding COVID-induced ARDS already described an increased use of tracheostomy, in line with our findings, ranging from $32 \%$ up to $60 \%$ [13-16].

The major contributing factor to this high incidence of tracheostomies might be the fact that patients with COVID-induced ARDS seem to require more time to improve, as compared to "classic" ARDS [13]. Indeed, in our population, the median ICU length of stay was 14 (9-27) days, which is longer as compared to the 10 (5-20) of the LUNG SAFE [12]. The reasons for this longer ICU length of stay have not been fully understood. It is conceivable that several aspects related to COVID's pathophysiology, such as the marked vascular and endothelial involvement [14], a high rate of secondary bacterial infections [15], and a high incidence of barotrauma [16-19], contribute to the longer course of the disease. Indeed, a high rate of bacterial infections is reported also in our cohort of patients, more frequently in tracheostomized patients with a longer duration of stay.

Another aspect that deserves discussion is the high percentage of surgical tracheostomies in our cohort. Italy has been the first European country hit by the 2020 pandemic. In spring 2020, the knowledge about the novel beta-coronavirus was extremely scarce and no data were available about the safety of healthcare professionals performing tracheostomies in infected patients. Performing a tracheostomy is certainly a procedure at very high risk for infection. In addition, the generation of aerosol particles, potentially containing the virus, is certainly favored in critically ill patients by the necessity to use high positive intrathoracic pressures. The idea that a surgical approach would be safer for the operator and the fact that surgeons were relatively free, due to the suspension of elective surgery, explain our finding. There is no evidence to recommend one method over the others and the daily availability of experienced surgical team avoided delays. Moreover, percutaneous tracheostomy involves more extensive manipulation of the airway with increased aerosolization risk [20]. In addition, it is certainly true that a surgical tracheostomy guarantees an easier cannula repositioning in case of accidental removal. This aspect might be of particular importance in the context of a pandemic surge, characterized by the presence of inexperienced doctors and nurses in the ICU. Of note, several studies described that the surgical technique was not associated with higher complication rates [21-23].

In our study, we compared the characteristics of patients in whom a tracheostomy was performed with those ventilated exclusively via an endotracheal tube (Table 1). The major difference was a longer disease course in tracheostomized patients, as demonstrated by a longer duration of mechanical ventilation and longer ICU and hospital length of stay. Tracheostomized patients developed bacterial infections more often. No difference in mortality was observed in the two groups. Of course, our data are purely descriptive and no conclusions on the effect of tracheostomy on COVID-ARDS can be drawn.

Other authors investigated the use of tracheostomy in SARS-CoV-2 patients, describing the overall safety of the procedure [22, 24-32]. Several studies reported a longer ICU length of stay in tracheostomized patients [25, 33].

The cohort of the Queen Elizabeth Hospital in Birmingham [25], is the only one describing a higher 30-day survival in patients undergoing tracheostomy as compared to patients that did not. While the authors accounted for disease severity in their analysis, it is important to underline the observational, non-randomized nature of the study.

Finally, in the present study, we focused our attention on tracheomalacia. Several factors are considered a risk for the development of tracheomalacia. In the general adult population, the most important one seems to be chronic inflammation, in the context of chronic obstructive pulmonary disease [9]. On the other hand, despite less evidence, trauma, infections, prolonged intubation, and tracheostomy have been considered potential risk factors [34-37]. 
In our cohort, in 8 of 151 patients (5\%), tracheomalacia was suspected clinically and confirmed with a fiberoptic evaluation. To the best of our knowledge, this is the largest report of tracheomalacia in COVID patients. A single case of tracheomegaly, with clinical features similar to our patients, was recently described [38].

The observed $5 \%$ percentage is higher as compared to the scarce literature, only referring to non-COVID patients. Karimpour and colleagues [39] describe that $0.6 \%$ out of 184 patients who underwent percutaneous Ciaglia tracheostomy in the ICU developed tracheomalacia, while Kandaswamy et al. describe an incidence of $0.7 \%$ in a case-control study including 576 mechanically ventilated patients, regardless of the presence of a tracheostomy [40]. Several factors could explain the observed higher incidence. On the one hand, a vascular and endothelial involvement in patients with COVID-19 has been described [41], particularly in the lungs. To the best of our knowledge the microvascular involvement of the upper airways has not been documented so far, however, from a surgical perspective, we observed a macroscopic impairment of the vascularization of tracheal and peri-tracheal tissues.

Another factor potentially implied with the pathogenesis of tracheomalacia in this particular pandemic context is an excessive cuff pressure of the endotracheal/tracheostomy tube [47] leading to tracheal wall suffering. Usually, great attention is paid to this aspect by the nursing staff. However, on the one hand, the presence of inexperienced nurses, recruited from regular wards due to the extremely high number of patients in need, and on the other hand, the fear of infection due to cuff leakage and viral spread could have resulted in overall higher cuff pressures. Finally, it is conceivable to hypothesize a role of mechanical trauma of the tracheostomy tube on the tracheal wall during pronation.

In our cohort, patients diagnosed with tracheomalacia had a significantly longer clinical course (ICU and hospital length of stay) a higher rate of bacterial infections, but a similar mortality. In addition, we observed that patients diagnosed with tracheomalacia had a higher body mass index, were more frequently female and that the use of tracheostomy was higher.

On the one hand, the physiologic gender-related differences in connective tissue $[42,43]$ could maybe explain the observed higher incidence in females. On the other hand, the higher body mass index, already identified as a potential risk factor [39], could be explained by the proinflammatory effect of obesity $[44,45]$ and a more difficult surgical or percutaneous access to the trachea during the performance of the tracheostomy. Moreover, obesity and obstructive sleep apneas might favor the development of tracheomalacia as a result of periodic markedly negative intrathoracic pressures generated during episodes of obstruction [46]. Of course, this would imply that at least a mild form of tracheomalacia was already present before the COVID infection and was somehow exacerbated during the critical illness.

Finally, the higher incidence of infections and the longer course of antibiotic therapy in the group of patients with tracheostomy and with tracheomalacia should be commented on. Certainly, the longer duration of ICU stay could simply have increased the probability of developing new bacterial infections, but the impact of repetitive infective events and the consequent systemic inflammation might have contributed to the pathophysiology of tracheomalacia.

The management of acquired tracheomalacia associated with mechanical ventilation is difficult and requires a multidisciplinary approach, involving critical care physicians, anesthesiologists, thoracic surgeons, and respiratory therapists. The approach might be surgical [34, 37, 48], endoscopic stent placement $[34,37,49]$ or conservative management with cycles of positive pressure ventilation [34, 40]. In our cohort of patients, a conservative approach, based on spontaneous breathing cycles and positive pressure after decannulation, was successful in patients with isolated tracheomalacia, i.e., in patients that had not developed a tracheoesophageal fistula.

\section{Limitations}

Several limitations of our study need to be mentioned. First, its retrospective, single-center nature. Second, the related limited sample size and associated statistical limitations. Third, the absence of data regarding common tracheostomy complications, such as bleeding and infection. Moreover, a fiberoptic evaluation was performed only in patients in whom tracheomalacia was suspected clinically. It is therefore conceivable that some cases of tracheomalacia were missed either in case of mild forms, not triggering a fiberoptic evaluation, or in patients who died before extubation/decannulation. The real incidence of tracheomalacia could therefore be higher.

\section{Conclusions}

In our cohort of 151 critically ill patients with COVID-related ARDS, we observed that almost $50 \%$ of mechanically ventilated patients were tracheostomized. This percentage is significantly higher as compared to the "classic" ARDS population. Furthermore, we observed that $5 \%$ of the studied population was diagnosed with tracheomalacia. Again, this percentage is significantly higher than the available reports of non-COVID ICU patients. Obesity, female gender, and tracheostomy might play a role in the development of this rare and severe condition.

\section{Abbreviations}

Obesity: Body Mass Index BMI > $30 \mathrm{~kg} / \mathrm{m}^{2}$ 
Chronic Ischemic Cardiovascular disease: congestive heart failure and previous acute coronary syndrome (excluding hypertension)

Chronic Kidney Failure: Glomerular Filtration Rate GFR $<59 \mathrm{ml} / \mathrm{min}$

Neoplasia: hematological malignancy, and solid tumors

Chronic Obstructive Respiratory Disease: asthma and COPD

Immunosuppression: HIV and AIDS, pharmacologic immunosuppression

ARDS mild: $\mathrm{P} / \mathrm{F}>200$ and $\leq 300$ with PEEP $>5 \mathrm{cmH} 20$

ARDS moderate: $\mathrm{P} / \mathrm{F}>100$ and $\leq 200$ with $\mathrm{PEEP}>5 \mathrm{cmH} 2 \mathrm{O}$

ARDS severe: $\mathrm{P} / \mathrm{F} \leq 100$ with $\mathrm{PEEP}>5 \mathrm{cmH} 2 \mathrm{O}$

Infection: positivity of microbiological test that requires Antibiotic therapy

Sepsis: organ dysfunction represented by an increase in the SOFA score $\geq 2$ points

Septic shock: a subset of sepsis requiring vasopressor to maintain a mean arterial pressure of $65 \mathrm{~mm} \mathrm{Hg}$ or greater and serum lactate level greater than $2 \mathrm{mmol} / \mathrm{L}(>18 \mathrm{mg} / \mathrm{dL})$ in the absence of hypovolemia

Bacterial Pneumonia: positivity of bronchial aspirate or bronchoalveolar lavage that requires antibiotic therapy

Bloodstream Infection: positivity of blood cultures that required antibiotic therapy

\section{Declarations}

\section{- Ethics approval and consent to participate}

The study was approved by the Local Ethical Committee (approval number: 593-06102020). The need for informed consent from individual patients was waived owing to the retrospective nature of the study.

\section{- Consent for publication}

Not applicable

\section{- Availability of data and materials}

All data generated or analysed during this study are included in this published article [and its supplementary information files].

\section{- Competing interests}

The authors declare that they have no competing interests.

\section{- Funding}

This study was performed with departmental funds only.

\section{- Authors' contributions}

MG, PA, TL, RF designed the study and contributed to manuscript writing.

HG, TL, MG performed statistical analysis.

RG, MB, SC, MG and HG collected the data.

GC, OC, MM, OM, RF contributed with data interpretation and manuscript writing.

All the authors approved the final manuscript submitted to this Journal.

\section{- Acknowledgements}

NA 


\section{References}

1. Huang C, Wang Y, Li X, Ren L, Zhao J, Hu Y, et al. Clinical features of patients infected with 2019 novel coronavirus in Wuhan, China. Lancet. Elsevier; 2020;395:497-506.

2. Guan W-J, Ni Z-Y, Hu Y, Liang W-H, Ou C-Q, He J-X, et al. Clinical Characteristics of Coronavirus Disease 2019 in China. N Engl J Med. 2020;382:1708-20.

3. Wang D, Hu B, Hu C, Zhu F, Liu X, Zhang J, et al. Clinical Characteristics of 138 Hospitalized Patients With 2019 Novel Coronavirus-Infected Pneumonia in Wuhan, China. JAMA. American Medical Association; 2020;323:1061-9.

4. Grasselli G, Zangrillo A, Zanella A, Antonelli M, Cabrini L, Castelli A, et al. Baseline Characteristics and Outcomes of 1591 Patients Infected With SARS-CoV-2 Admitted to ICUs of the Lombardy Region, Italy. JAMA. 2020;323:1574-81.

5. Bonalumi G, Giambuzzi I, Barbone A, Ranieri C, Cavallotti L, Trabattoni P, et al. A call to action becomes practice: cardiac and vascular surgery during the COVID-19 pandemic based on the Lombardy emergency guidelines. Eur J Cardiothorac Surg. 2020;58:319-27.

6. Spina S, Marrazzo F, Migliari M, Stucchi R, Sforza A, Fumagalli R. The response of Milan's Emergency Medical System to the CoVID-19 outbreak in Italy. Lancet. Elsevier; 2020;395:e49-50.

7. Raimondi N, Vial MR, Calleja J, Quintero A, Cortés A, Celis E, et al. Evidence-based guidelines for the use of tracheostomy in critically ill patients. J Crit Care. 2017;38:304-18.

8. Fernandez-Bussy S, Mahajan B, Folch E, Caviedes I, Guerrero J, Majid A. Tracheostomy Tube Placement: Early and Late Complications. J Bronchology Interv Pulmonol. 2015;22:357-64.

9. Carden KA, Boiselle PM, Waltz DA, Ernst A. Tracheomalacia and tracheobronchomalacia in children and adults: an in-depth review. Chest. 2005;127:984-1005.

10. Foti G, Giannini A, Bottino N, Castelli GP. Management of critically ill patients with COVID-19: suggestions and instructions from the coordination of intensive care units of Lombardy. Minerva [Internet]. europepmc.org; 2020; Available from: https://europepmc.org/article/med/33228329

11. Abe T, Madotto F, Pham T, Nagata I, Uchida M, Tamiya N, et al. Epidemiology and patterns of tracheostomy practice in patients with acute respiratory distress syndrome in ICUs across 50 countries. Crit Care. 2018;22:195.

12. Bellani G, Laffey JG, Pham T, Fan E, Brochard L, Esteban A, et al. Epidemiology, Patterns of Care, and Mortality for Patients With Acute Respiratory Distress Syndrome in Intensive Care Units in 50 Countries. JAMA. 2016;315:788-800.

13. Ferrando C, Suarez-Sipmann F, Mellado-Artigas R, Hernández M, Gea A, Arruti E, et al. Clinical features, ventilatory management, and outcome of ARDS caused by COVID-19 are similar to other causes of ARDS. Intensive Care Med. 2020;46:2200-11.

14. Varga Z, Flammer AJ, Steiger P, Haberecker M, Andermatt R, Zinkernagel AS, et al. Endothelial cell infection and endotheliitis in COVID-19. Lancet. 2020;395:1417-8.

15. Lansbury L, Lim B, Baskaran V, Lim WS. Co-infections in people with COVID-19: a systematic review and meta-analysis. J Infect. 2020;81:266-75.

16. Lemmers DHL, Abu Hilal M, Bnà C, Prezioso $C$, Cavallo $E$, Nencini N, et al. Pneumomediastinum and subcutaneous emphysema in COVID-19: barotrauma or lung frailty? ERJ Open Res [Internet]. 2020;6. Available from: http://dx.doi.org/10.1183/23120541.00385-2020.

17. Udi J, Lang CN, Zotzmann V, Krueger K, Fluegler A, Bamberg F, et al. Incidence of Barotrauma in Patients With COVID-19 Pneumonia During Prolonged Invasive Mechanical Ventilation-A Case-Control Study. J Intensive Care Med. SAGE Publications Sage CA: Los Angeles, CA; 2020;0885066620954364.

18. McGuinness G, Zhan C, Rosenberg N, Azour L, Wickstrom M, Mason DM, et al. Increased Incidence of Barotrauma in Patients with COVID-19 on Invasive Mechanical Ventilation. Radiology. 2020;297:E252-62.

19. Protti A, Greco M, Filippini M, Vilardo AM, Langer T, Villa M, Frutos-Vivar F, et al. Barotrauma in Mechanically-Ventilated Patients with Coronavirus Disease 2019: A Survey of 38 Hospitals in Lombardy, Italy. Minerva Anestesiologica, December, 2020. Available from: https://doi.org/10.23736/S0375-9393.20.15002-8.

20. Tay JK, Khoo ML, and Loh WS. Surgical Considerations for Tracheostomy During the COVID-19 Pandemic. JAMA Otolaryngology-Head \& Neck Surgery, 2020 Available from: https://doi.org/10.1001/jamaoto.2020.0764.

21. Long SM, Chern A, Feit NZ, Chung S, Ramaswamy AT, Li C, et al. Percutaneous and Open Tracheostomy in Patients with COVID-19: Comparison and Outcomes of an Institutional Series in New York City. Ann Surg [Internet]. journals.Iww.com; 2020; Available from: http://dx.doi.org/10.1097/SLA.0000000000004428.

22. Botti C, Lusetti F, Neri T, Peroni S, Castellucci A, Salsi P, et al. Comparison of percutaneous dilatational tracheotomy versus open surgical technique in severe COVID-19: Complication rates, relative risks and benefits. Auris Nasus Larynx [Internet]. 2020; Available from: http://dx.doi.org/10.1016/j.anl.2020.10.014. 
23. Krishnamoorthy S, Polanco A, Coleman N, Prigoff J, Sturm J, Blitzer D, et al. The Safety and Efficacy of Tracheostomy in Patients Diagnosed with COVID-19: An Analysis of 143 patients at a Major NYC Medical Center. Ann Surg [Internet]. 2020; Available from: http://dx.doi.org/10.1097/SLA.0000000000004612.

24. Mishra P, Jedge P, Kaushik M, Artham P, Kumari S. Our Experience of Tracheostomy in COVID-19 Patients. Indian J Otolaryngol Head Neck Surg. 2020;1-4.

25. Queen Elizabeth Hospital Birmingham COVID-19 airway team. Safety and 30-day outcomes of tracheostomy for COVID-19: a prospective observational cohort study. Br J Anaesth [Internet]. 2020; Available from: http://dx.doi.org/10.1016/j.bja.2020.08.023

26. Vargas M, Russo G, lacovazzo C, Servillo G. Modified percutaneous tracheostomy in COVID-19 critically ill patients. Head Neck [Internet]. Wiley Online Library; 2020; Available from: https://onlinelibrary.wiley.com/doi/abs/10.1002/hed.26276? casa_token=CGtGgObvKOoAAAAA:g74R80kGbg50xgdAdNmavS2GNhbHL6K5Svsfo1N3xYo97XRG6Pv7zkIY0qK06qTC3AYA3KJCY9b69Pep

27. Zhang X, Huang Q, Niu X, Zhou T, Xie Z, Zhong Y, et al. Safe and effective management of tracheostomy in COVID-19 patients. Head Neck. 2020;42:1374-81.

28. Chao TN, Harbison SP, Braslow BM, Hutchinson CT, Rajasekaran K, Go BC, et al. Outcomes after Tracheostomy in COVID-19 Patients. Ann Surg [Internet]. 2020; Available from: http://dx.doi.org/10.1097/SLA.0000000000004166

29. Avilés-Jurado FX, Prieto-Alhambra D, González-Sánchez N, de Ossó J, Arancibia C, Rojas-Lechuga MJ, et al. Timing, Complications, and Safety of Tracheotomy in Critically III Patients With COVID-19. JAMA Otolaryngol Head Neck Surg [Internet]. 2020; Available from: http://dx.doi.org/10.1001/jamaoto.2020.3641

30. Kim EJ, Yoo E-H, Jung CY, Kim KC. Experience of percutaneous tracheostomy in critically ill COVID-19 patients. Acute Crit Care [Internet]. 2020; Available from: http://dx.doi.org/10.4266/acc.2020.00444

31. Taboada M, Vazquez S, Regueira J, Cariñena A, Aneiros F, Caruezo V, et al. Safe percutaneous dilational tracheostomy in 5 patients with ARDS by Covid-19. J Clin Anesth. 2020;67:109977.

32. Botti C, Lusetti F, Peroni S, Neri T, Castellucci A, Salsi P, et al. The Role of Tracheotomy and Timing of Weaning and Decannulation in Patients Affected by Severe COVID-19. Ear Nose Throat J. 2020;145561320965196.

33. Zuazua-Gonzalez A, Collazo-Lorduy T, Coello-Casariego G, Collazo-Lorduy A, Leon-Soriano E, Torralba-Moron A, et al. Surgical Tracheostomies in COVID-19 Patients: Indications, Technique, and Results in a Second-Level Spanish Hospital. OTO Open. 2020;4:2473974X20957636.

34. Kandaswamy C, Balasubramanian V. Review of adult tracheomalacia and its relationship with chronic obstructive pulmonary disease. Curr Opin Pulm Med. 2009;15:113-9.

35. Chang CY, Thomas JP. Adult-onset iatrogenic tracheomalacia. Ear Nose Throat J. 2008;87:312-4.

36. Tempe DK, Goel S. Over-distended tracheostomy tube cuff: a sign of tracheomalacia. Ann Card Anaesth. 2007;10:154.

37. Kugler C, Stanzel F. Tracheomalacia. Thorac Surg Clin. 2014;24:51-8.

38. Harper S, Robinson M, Manning G, Jones A, Hobson J, Shelton CL. Management of tracheostomy-related tracheomegaly in a patient with COVID-19 pneumonitis. Anaesthesia Reports. 2020;8:157-60.

39. Karimpour HA, Vafaii K, Chalechale M, Mohammadi S, Kaviannezhad R. Percutaneous Dilatational Tracheostomy via Griggs Technique. Arch Iran Med. 2017;20:49-54.

40. Kandaswamy C, Bird G, Gill N, Math E, Vempilly JJ. Severe tracheomalacia in the ICU: identification of diagnostic criteria and risk factor analysis from a case control study. Respir Care. 2013;58:340-7.

41. Ackermann M, Verleden SE, Kuehnel M, Haverich A, Welte T, Laenger F, Vanstapel A, et al. Pulmonary Vascular Endothelialitis, Thrombosis, and Angiogenesis in Covid-19. The NEJM. 2020;383(2):120-28.

42. Chidi-Ogbolu N, Baar K. Effect of Estrogen on Musculoskeletal Performance and Injury Risk. Front Physiol. 2018;9:1834.

43. Leblanc DR, Schneider M, Angele P, Vollmer G, Docheva D. The effect of estrogen on tendon and ligament metabolism and function. J Steroid Biochem Mol Biol. 2017;172:106-16.

44. Rocha VZ, Libby P. Obesity, inflammation, and atherosclerosis. Nat Rev Cardiol. 2009;6:399-409.

45. Cox AJ, West NP, Cripps AW. Obesity, inflammation, and the gut microbiota. Lancet Diabetes Endocrinol. 2015;3:207-15.

46. Kolakowski CA, Rollins DR, Jennermann T, Stevens AD, Good JT, Denson JL, et al. Clarifying the link between sleep disordered breathing and tracheal collapse: a retrospective analysis. Sleep Science and Practice. 2018;2:10.

47. Silva LU, Wood GJ. Tracheomalacia from Excessive Cuff Pressure of an Endotracheal Tube. Ann Saudi Med. King Faisal Specialist Hospital and Research Centre; 1984;4:201-3.

48. Cho JH, Kim H, Kim J. External tracheal stabilization technique for acquired tracheomalacia using a tailored silicone tube. Ann Thorac Surg. 2012;94:1356-8.

49. Pizarro C, Dabir D, Nickenig G, Skowasch D. Nitinol stent insertion in tracheomalacia. Thorax. 2016;71:770-1.

Page 10/11 
Figures

177 patients with laboratory-confirmed

SARS-CoV-2 infection admitted to ICU

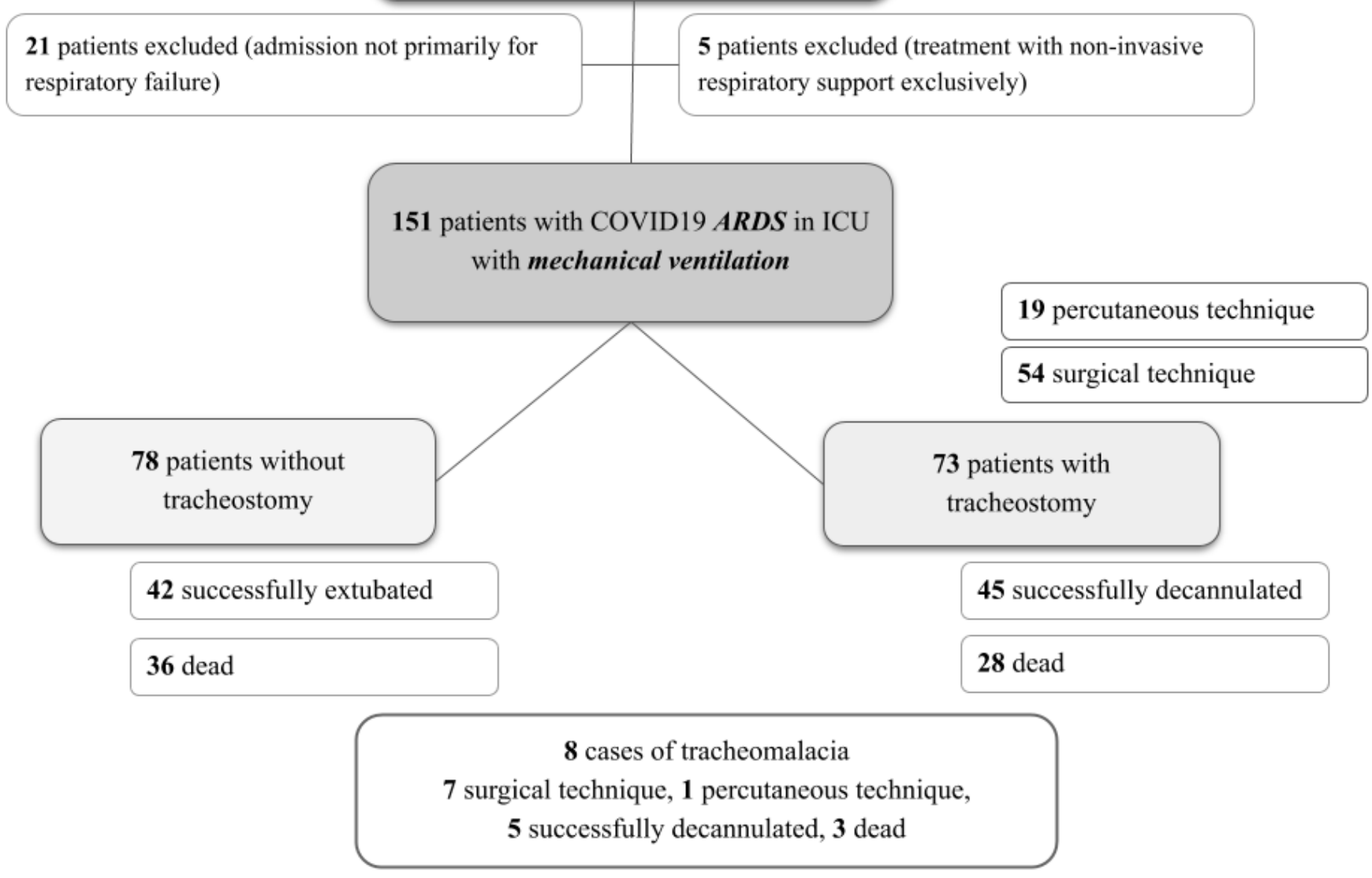

Figure 1

Flow diagram

\section{Supplementary Files}

This is a list of supplementary files associated with this preprint. Click to download.

- STROBEchecklistv4combined.docx 